\title{
DAIRY PRODUCTION IN BELARUS: STANDARDS, REGULATIONS AND QUALITY STANDARDS
}

\author{
ПРОИЗВОДСТВО МОЛОЧНОЙ ПРОДУКЦИИ В РЕСПУБЛИКЕ БЕЛАРУСЬ: \\ СТАНДАРТЫ, РЕГЛАМЕНТЫ И ТРЕБОВАНИЯ К КАЧЕСТВУ
}

\section{Kovalev, Candidate of Economic Sciences, Associate Professor}

Л.И. Ковалёв, кандидат экономических наук, доцент

\author{
I. Kovalev, Engineer-Economist \\ И.Л. Ковалёв, инженер-экономист
}

\begin{abstract}
Belarusian State Agrarian Technical University, Minsk, Republic of Belarus
Белорусский государственный аграрный технический университет, г. Минск, Республика Беларусь Phone: (+375 29) 391-51-11, (+375 29) 126-69-12

E-mail: olbosigor@mail.ru
\end{abstract}

Received September 21, 2012

\begin{abstract}
The paper presents a brief analysis of the procedures and requirements for the quality and the production of milk in Belarus from the Soviet Union, and to this day, consider some areas of the dairy industry in the Republic of Belarus for 2011-2015, to look at issues and characteristics of milk production in the country. The article raised some important task of unification of Russian and Belarusian industry regulations and standards.
\end{abstract}

\section{АННОТАЦИЯ}

В статье приведен краткий анализ регламентов и требований к качеству и производству молока в Беларуси со времен Советского Союза и по сегоднямний день, рассмотрены некоторые направления развития молочной отрасли Республики Беларусь на 2011-2015 г2., уделено внимание вопросам и особенностям производства молока в республике. В статье подняты отдельные важные задачи по унификации российских и белорусских отраслевых регламентов и стандартов.

\section{KEY WORDS}

Dairy cattle; Milk quality; Technical regulations; Standards.

\section{КЛЮЧЕВЫЕ СЛОВА}

Молочное животноводство; Качество молока; Технический регламент; Стандартыл.

В текущей пятилетке развитие агропромышленного комплекса Республики Беларусь определяется 17 программами. Основные задачи и цели по производству молока определены Республиканской программой развития молочной отрасли на 2011-2015 гг. Программой развития молочной отрасли предусматривается продолжение строительства начатого в ушедшей пятилетке, современных молочнотоварных ферм и реконструкция ныне работающих, так в 2011-2015 годы предполагается построить 875 новых и произвести реконст- рукцию 1360 действующих ферм. В настоящее время в республике функционируют около пяти тысяч молочно-товарных ферм. Из них на 1 января 2012г. реконструировано и построено новых - 1510 , или около $30 \%$ от общего количества ферм.

В тоже время, следует отметить, что в республике до сих пор на 1470 молочнотоварных фермах применяется устаревшая неэффективная и затратная технология по производству молока, которая основана на привязном содержании коров с доением в пе- 
реносные ведра на линейных доильных установках. На указанных фермах содержатся около 308-310 тысяч коров, а их доля в общем объеме производства молока составляет свыше $22 \%$.

Дальнейшее увеличение производства молока, необходимое для удовлетворения спроса населения, обеспечения его молоком и молочными продуктами в соответствии с научно обоснованными физиологическими нормами, а также значительное увеличение экспортных поставок, невозможно без перевода молочного скотоводства на индустриальнопромышленную основу. На мелких фермах практически невозможно с высоким экономическим эффектом внедрить индустриальные методы производства молока, прогрессивную технологию, использовать высокопроизводительные машины и современное оборудование, рассчитанное на крупные фермы промышленного типа, новейшие системы содержания скота, научную организацию труда и производства.

На фермах-комплексах по сравнению с существующими мелкими фермами производительность труда должна повыситься в 5-8 раз. В настоящее время в нашей стране идет процесс концентрации и специализации производства молока, который преследует цель укрупнения ферм, доведения их до размера, позволяющего внедрить прогрессивную технологию. На них можно использовать новейшие машины и механизмы и производить молоко с небольшими затратами труда и средств. Уровень такой концентрации производства доступен и экономически оправдан в большинстве хозяйств. Это достигается путем реконструкции и расширения имеющихся ферм.

Наиболее оптимальными для промышленной технологии являются фермы на 600800 коров. Вблизи областных центров и крупных промышленных городов перспективны молочные комплексы на 1000-1200 коров. В тоже время в республике строятся комплексы«гиганты» на 2000-2100 коров.

Промышленная технология производства молока базируется на наиболее прогрессивной беспривязной боксовой системе содержания коров, биологически полноценном кормлении, использовании полнорационных кормосмесей, новейших методов комплектования и воспроизводства стада, на интенсивном использовании животных. Весь технологиче- ский процесс строится в республике в основном по двухцикличной системе организации производства и труда - двукратные раздача кормов и доение с использованием высокопроизводительных доильных площадок различных конструкций.

Важная задача молочного производства целенаправленная работа по повышению качества молока и, особенно по увеличению содержания в нем основных питательных компонентов.

Работникам, занятым производством молока, необходимо помнить, что этот продукт имеет свои специфические особенности, которые существенно отличают его от других продуктов сельскохозяйственного производства. Молоко в хозяйствах получают в течение всего года. Оно не может длительно храниться, это вызывает необходимость перерабатывать его в кратчайшие сроки после получения.

Качество вырабатываемых молочных продуктов зависит от условий получения молока в хозяйстве (содержание стада, качество кормов, здоровье животных и др.). Как бы ни была совершенна технология переработки, из молока с высокой кислотностью, большой механической загрязненностью и бактериальной обсемененностью нельзя приготовить высококачественные молочные продукты. Учитывая эти особенности молока, следует уделять постоянное внимание сохранению его качества и натуральных свойств.

Для большей полноты настоящего исследования приведем некоторые важные и интересные факты и цифры из нашего недалёкого прошлого.

В молочном производстве во времена СССР был разработан и повсеместно внедрен первый единый для всей страны ГОСТ 1326470 «Молоко коровье. Требования при заготовках», также одновременно были введены новые повышенные цены на молоко, закупаемое государством, дифференцированные в зависимости от его качества. Пересмотрены некоторые положения «Инструкции о порядке сдачи - приема молока государству». Уточнены нормы базисной жирности молока по отдельным районам страны. На многих молочных фермах довольно успешно применялась система управления качеством труда и продукции. В то время и было положено начало переводу молочного скотоводства на про- 
мышленную основу. Благодаря введению ГОСТа 13264-70, а также дифференциации закупочных цен на молоко в зависимости от его сортности качество молока заметно улучшилось и уже в 1980г. в Белоруссии было закуплено 82\% всего молока первым сортом, согласно ГОСТу 13264-70 первый сорт соответствовал самой высокой категории качества молока на то время (табл.1).

Основным документом, определяющим взаимоотношения между сельскохозяйственными предприятиями и предприятиями молочной промышленности, являлась «Инструкция о порядке проведения государственных закупок (сдачи и приема) молока и молочной продукции», утвержденная 6 апреля 1973 г. и введенная в действие 1 января 1974 г. В соответствии с этим документом молоко, продаваемое государству, должно отвечать требованиям ГОСТа 13264-70 «Молоко коровье. Требования при заготовках».

Согласно ГОСТу молоко, продаваемое государству, должно быть получено от здоровых животных, быть цельным и свежим, а ус- ловия его получения должны соответствовать требованиям санитарных и ветеринарных правил для молочных ферм колхозов и совхозов. Молоко должно быть профильтровано и охлаждено. В отдельных случаях ГОСТ допускал по согласованию с предприятиями молочной промышленности и органами санитарного и ветеринарного надзора прием парного молока без охлаждения в течение часа после выдаивания. Молоко должно быть чистое, без посторонних, не свойственных свежему сырому молоку привкусов и запахов. По внешнему виду и консистенции оно должно быть однородной жидкостью без осадка и хлопьев. Цвет молока должен быть от белого до слабо-желтого. Плотность молока должна

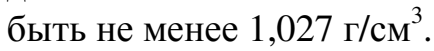

В зависимости от физико-химических и санитарно-гигиенических показателей молоко делилось на четыре качественные категории: первый сорт, первый сорт охлажденное, второй сорт и несортовое. Требования к этим товарным категориям молока представлены в табл. 1.

Таблица 1 - Категории качества молока в соответствии с ГОСТом 13264-70

\begin{tabular}{|c|c|c|c|c|}
\hline Показатели & Первый сорт & $\begin{array}{l}\text { Первый сорт } \\
\text { охлажденное }\end{array}$ & Второй сорт & Несортовое \\
\hline Кислотность, ${ }^{\mathrm{T}}$, не более & $16-18$ & $16-18$ & $16-20$ & $21-23$ \\
\hline $\begin{array}{l}\text { Степень чистоты по эталону } \\
\text { не ниже, группы }\end{array}$ & I & I & II & II \\
\hline $\begin{array}{c}\text { Бактериальная обсеменен- } \\
\text { ность, не ниже класса }\end{array}$ & I & I & II & III \\
\hline Температура, ${ }^{\circ} \mathrm{C}$ & не учитывается & не выше $10^{\circ}$ & не учитывается & не учитывается \\
\hline
\end{tabular}

Содержание жира определяется при приеме молока, а затем производится пересчет на базисную жирность. В БССР она была определена в 3,4\%. С 1 января 1979 г. в СССР были повышены закупочные цены на молоко, животное масло и сливки. С повышением закупочных цен на молоко они в ряде случаев стали выше действующих розничных цен. За продаваемое колхозами, совхозами и другими хозяйствами молоко первого сорта с температурой на момент приемки не выше $10^{\circ} \mathrm{C}$ дополнительно к закупочной цене выплачивалась надбавка в размере 5 руб. за тонну молока базисной жирности $(3,4 \%)$. Приемка молока и определение его качества производились в присутствии сдатчика.

Согласно действовавшему ГОСТу бактериальная обсемененность молока определяется по редуктазной пробе один раз в декаду и дополнительно не более одного раза в декаду по просьбе сдатчика. Результаты анализа по определению класса молока распространялись на все молоко, принятое в период до следующего анализа.

Молоко от больных или подозреваемых в заболевании коров, если оно на ферме подвергается пастеризации, принимается как молоко второго сорта.

Оплата за молоко строго дифференцирована по сортам. Причем цены на молоко все время совершенствуются, пересматриваются. Не подлежит приему молоко, полученное в первые и в последние 7 дней лактации, содержащее остатки консервирующих и нейтрализующих веществ, с запахом химикатов и нефтепродуктов, с остатками пестицидов и со следами антибиотиков, с прогорклым вкусом, а также с привкусом лука, чеснока, полыни и 
т. п. Молоко, поставляемое непосредственно в торговую сеть, должно было соответствовать ГОСТу 13277-67 «Молоко коровье пастеризованное».

Расчеты с колхозами и совхозами за принятое молоко производились за каждую пятидневку, а с населением - не реже двух раз в месяц. При доставке молока от населения колхозным или совхозным транспортом расходы за доставку возмещались в установленном порядке. Предприятия молочной промышленности возмещали колхозам и совхозам за каждую тонну закупаемого и доставляемого молока от населения в размере 20 руб.

Вместе с расчетами за молоко колхозам, совхозам и другим хозяйствам оплачивалась стоимость доставки молока, исходя из его физического веса, включая вес тары (фляги, бидоны), по единым тарифам на перевозку грузов автомобильным транспортом. При доставке молока специализированным транспортом расходы возмещались за фактический вес продукции (без массы тары) с дополнительной выплатой надбавок за специализированный транспорт. Оплата за доставку молока хозяйствам при заезде автотранспортом (при одном и том же рейсе) за грузом на несколько ферм производилась за расстояние от пункта первой погрузки до пункта последней разгрузки на приёмном пункте за все количество груза. При доставке молока с одной фермы оплата ведется за расстояние от этой фермы до пункта сдачи.

Погрузка молока и молочной продукции и выгрузка тары производится силами и средствами хозяйств, а разгрузка транспорта с продукцией и погрузка возвращаемой тары силами и средствами предприятий молочной промышленности.

В целях стимулирования сверхплановой продажи молока государством была установлена надбавка в размере 50\% к закупочной цене. Исчислялась надбавка с учетом сумм, выплаченных за охлаждение молока I сорта до $10^{\circ} \mathrm{C}$. Основанием для выплаты надбавки за сверхплановую продажу являлся акт сверки данных о выполнении годового плана, составленный хозяйством и подтвержденный райинспекцией ЦСУ и инспекцией по закупкам и качеству сельхозпродукции.

Принятые меры в 1971-1979 гг. по повышению качества молока, а также повышение материальной заинтересованности при его производстве путем увеличения закупочных цен, установление надбавок за сверх продажи государству и надбавка за охлажденное молоко позволили увеличить объем производства молока по стране за этот период на 35\%. Также в значительной степени возрос объем производства молока по сравнению с 1966 годом по отдельным союзным республикам и соответственно в целом по стране. В 1966 году в СССР было произведено молока 45,8 млн. тонн, а в 1979 году - 65,8 млн. тонн или рост составил $143 \%$. По республикам: в РСФСР в 1966 г.- 25,8 млн. тонн, а в 1979 г. - 35,7 или увеличение на $138 \%$, на Украине 10,8 и 15,8 или $145 \%$, в Белоруссии 2,4 и 4,2 или $173 \%$ соответственно.

С 1 января 1991 года в Республике Беларусь действовал ГОСТ 13264-88 «Молоко коровье. Требования при закупках», который заменен СТБ 1598-2006 «Молоко коровье. Требования при закупках». С 1 января 2008 года в Беларуси введен новый сорт молока "Экстра" со вступлением в силу изменения N1 к СТБ 1598-2006. Этим же изменением из классификации исключено несортовое молоко.

По своим требованиям стандарт максимально приближен к требованиям регламента ЕС и Кодекса Алиментариус.

К молоку сорта "Экстра" предъявляются более высокие требования по качеству и безопасности (по количеству микроорганизмов, соматических клеток, белка).

Основные требования, предъявляемые к молоку:

- молоко должно быть получено от здоровых животных в хозяйствах, благополучных по инфекционным болезням, в соответствии с правилами ветеринарного законодательства, и по качеству соответствовать требованиям настоящего стандарта;

- молоко после дойки должно быть профильтровано (очищено) и охлаждено в хозяйстве, не позднее чем через 2 ч после дойки;

- молоко сырое при сдаче-приемке на предприятиях молочной промышленности должно иметь температуру не выше плюс $10^{\circ} \mathrm{C}$, а при сдаче-приемке в хозяйстве - не выше плюс $6^{\circ} \mathrm{C}$.

- молоко должно быть натуральным, белого или слабо-кремового цвета, без осадков и хлопьев. Замораживание молока не допускается; 
- молоко не должно содержать ингибирующих и нейтрализующих веществ (антибиотиков, аммиака, соды, перекиси водорода и др.);

- содержание в молоке тяжелых металлов, мышьяка, афлатоксина М1 и остаточных следов пестицидов не должно превышать максимально допустимого уровня, утвержденного Минздравом;

- молоко должно быть плотностью не менее $1027 \kappa г / \mathrm{M}^{3}$

В соответствии с СТБ 1598-2006 сырое молоко разделяют на три сорта - высший, первый и второй. Сорт молока определяется по показателям кислотности, степени чистоты и бактериальной обсемененности. Так, кислотность молока высшего и первого сорта должна находиться в пределах $16-18^{\circ} \mathrm{T}$. Молоко высшего сорта не должно содержать соматических клеток в $1 \mathrm{~cm}^{3}$ более 500 тыс., первого и второго - не более 1000 тыс., а бактериальная обсемененность не должна превышать: для молока "экстра" количество мик-

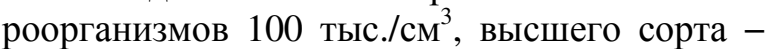

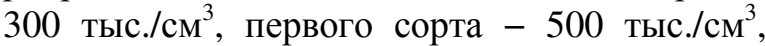

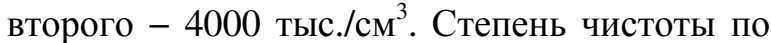
эталону должна быть не ниже I группы для высшего и первого сорта и не ниже II группы - для второго сорта.

Молоко, предназначенное для производства продуктов детского питания и стерилизованных продуктов, должно отвечать требованиям высшего или первого сорта, но с содержанием соматических клеток не более 500

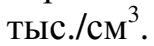

Во втором полугодие 2009 года Российская Федерация ограничила поставку белорусской молочной продукции на свой рынок из-за разногласий по некоторым аспектам качества поставляемой продукции. Переход России с января 2010 года на новый техрегламент, согласно которому содержание антибиотиков в молоке должно быть равным нулю, а также соответствовать и другим требованиям по качеству и безопасности Федерального закона № 88-Ф3 «Технический регламент на молоко и молочную продукцию» (табл. 2).

Таблица 2 - Требования к качеству и безопасности сырого молока в РФ

\begin{tabular}{|c|c|c|c|c|c|}
\hline \multirow[t]{2}{*}{ Показатели качества/безопасности } & \multicolumn{5}{|c|}{$\begin{array}{l}\text { Требования к качеству и безопасности сырого молока } \\
\text { сорта }\end{array}$} \\
\hline & «Люкс» & «Экстра» & Высший & Первый & Второй \\
\hline Температура, ${ }^{\circ} \mathrm{C}$ & 4 & 6 & 6 & 8 & 10 \\
\hline Цвет & \multicolumn{5}{|c|}{ От белого до светло-кремового } \\
\hline Консистенция & \multicolumn{5}{|c|}{$\begin{array}{c}\text { Однородная жидкость без осадка и хлопьев. } \\
\text { Замораживание не допускается. }\end{array}$} \\
\hline Вкус, запах, балл & 5 & 5 & 5 & 4 & 3 \\
\hline Кислотность, ${ }^{\circ}$, не более & 17 & 18 & 18 & 18 & 21 \\
\hline Плотность, кг/м ${ }^{3}$ не менее & 1028 & 1028 & 1028 & 1027 & 1027 \\
\hline 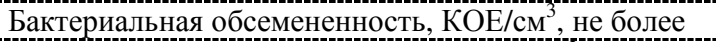 & 80000 & 80000 & 100000 & 500000 & 4 мЛн. \\
\hline Количество соматических клеток, тыс./см ${ }^{3}$, не более & 200 & 200 & 400 & 1000 & 1000 \\
\hline Температура замерзания, ${ }^{\circ} \mathrm{C}$ & $-0,520$ & $-0,520$ & $-0,520$ & $-0,520$ & $-0,520$ \\
\hline Термоустойчивость, группа, не ниже & I & II & II & III & IV \\
\hline Массовая доля белка, \%, не менее & 3,3 & 3,2 & 3,0 & 2,8 & 2,8 \\
\hline Массовая доля жира, \%, не менее & 3,5 & 3,4 & 3,0 & 2,8 & 2,8 \\
\hline Массовая доля СОМО, \%, не менее & 8,2 & 8,2 & 8,2 & 8,2 & 8,2 \\
\hline Ингибирующие вещества/ антибиотики & \multicolumn{5}{|c|}{ Отсутствуют } \\
\hline
\end{tabular}

В течение многих лет антибиотики используют для лечения инфекционных заболеваний коров, особенно мастита. В последнее время в результате все возрастающих требований к повышению производительности молочных коров участились случаи заболеваний животных, а следовательно, и применения антибиотиков.

Обычно молоко коров после курса лечения антибиотиками может использоваться только через определенное время. В зависимости от типа и дозировки антибиотика рекомендуемый карантин составляет в среднем 4-5 дней. Очень часто сроки карантина не выдерживаются, и молоко от больных животных поступает на молочный завод. Для молокоперерабатывающих предприятий остатки антибиотиков в молоке составляют серьезную проблему. Поскольку, ингибируя сквашивание, они могут нарушить производственный 
процесс, а также способствовать размножению посторонней, в том числе патогенной, микрофлоры. Поэтому их влияние может привести к значительным финансовым потерям для предприятия. Из-за антибиотиков несут финансовые потери и многие фермерские хозяйства, так как при приемке сырья, в котором обнаружен антибиотик, предприятиепереработчик значительно снижает цену.

Выбор оптимальных и эффективных методов контроля содержания антибиотиков в молоке-сырье - актуальная проблема и для перерабатывающих предприятий, и для производителей сырья.

Чтобы отвечать растущим требованиям к качеству и безопасности сырья и пищевых продуктов, в настоящее время зарубежные компании предлагают самые передовые технологии выявления остатков антибиотиков в коровьем, козьем и овечьем молоке. Для быстрого и надежного обнаружения антибиотиков в молоке предлагается целый ассортимент высокочувствительных экспресс-тестов. Они в основном представляются в виде полностью укомплектованных наборов на 25 и 250 определений содержащих все необходимое для проведения анализов, включая пробирки с лиофилизированным рецептором, индикаторные стержни, шприц-дозатор, одноразовые наконечники и полное описание методик проведения анализа.

Следует отметить, что в других странах коровы, которым дают антибиотики, обычно не доятся в течение нескольких недель, а тестирование на наличие этих препаратов в молоке проводят как сами фермеры, так и производители. При этом за продажу молока, содержащего остатки антибиотиков, предусмотрены немалые штрафы. В нашей республике, где не только крупные хозяйства, но мелкие фермы производят и сдают молоко, тестирование на антибиотики производителями проводится крайне редко. В упущениях по вопросам качества вина лежит исключительно на персонале ферм. Доярка в хозяйстве, зная, что корова больна и лечится медикаментами, должна отвести ее в сторону и не сливать «больное» молоко в общую емкость. Ведь даже когда оно смешивается с чистым сырьем, то антибиотиками загрязняется вся партия. Попадание загрязненного молока в общую емкость можно искоренить исключительно контролем на местах - это самый дешевый и рациональный путь. К примеру, одно лабораторное исследование молока на один вид антибиотика при проведении иммуноферментного анализа стоит порядка 100 тыс. бел. руб., а самый дешевый прибор - витебский «Витязь» - около 12-13 млн. бел. руб. Так что, гораздо дешевле - платить доярке премию за разделение чистого и загрязненного антибиотиками молока, нежели покупать и постоянно использовать такие дорогостоящие приборы, тесты и проводить столь недешевые анализы.

Ограничения на поставку белорусской молочной продукции начавшиеся летом 2009 года на российском направлении, в конечном итоге «помогли» Беларуси быстро переориентироваться и на другие внешние рынки. При этом стремление достичь жестких стандартов качества позволяет белорусским предприятиям усилить свои позиции на всех экспортных рынках.

С 1 января 2011 года в Республике Беларусь введен в действие технический регламент Республики Беларусь «Молоко и молочная продукция. Безопасность» (ТР 2010/018/BY), утвержденный Постановлением Совета Министров Республики Беларусь №431 от 25 марта 2010 г.

Указанный технический регламент распространяется на производимые в Республике Беларусь молоко и молочную продукцию, включая сырое молоко.

Техническим регламентом устанавливаются требования к безопасности молока и молочной продукции, процессам их производства, хранения, перевозки, реализации в целях защиты жизни, здоровья и наследственности человека, а также предупреждения действий, вводящих в заблуждение потребителей относительно назначения молока и молочной продукции, их качества или безопасности.

При этом технический регламент не распространяется на молоко и молочную продукцию, полученные в процессе непромышленного производства, в том числе предназначенные для домашнего использования, а также на материалы, контактирующие с пищевыми продуктами, требования к безопасности которых устанавливаются соответствующим техническим регламентом.

Сегодня в Беларуси стандарты качества молока куда более жесткие, чем даже в странах Европы. Так в государствах Евросоюза допускается содержание до 100 и более мик- 
рограммов на 1 килограмм молочной продукции антибиотиков (ограничение дозы зависит от вида препарата), у нас до недавнего времени было 50 микрограммов на 1 килограмм, в США- 1тыс.

В целях обеспечения гигиенических требований предъявляемых к молоку сельхозтоваропроизводители и молокоперерабатывающие предприятия должны руководствоваться Санитарными правилами и нормами 2.3.4.1319-2002 «Производство молока и молочных продуктов», которые разработаны на основе Закона Республики Беларусь «О санитарноэпидемическом благополучии населения», и устанавливают гигиенические требования к производству и производственному лабораторному контролю молока и молочных продуктов, обеспечивающие выпуск продукции соответствующей гигиеническим требованиям к качеству и безопасности.

Доброкачественное молоко должно отвечать трем требованиям: иметь нормальный химический состав, быть пригодным для переработки в различные продукты и не представлять опасности для потребителя. Молоко является хорошей средой для развития многих микроорганизмов. Если в молоко попадут болезнетворные бактерии, то оно может стать источником серьезных заболеваний человека.

Гигиеническое состояние молока определяется также его чистотой, общей бактериальной обсемененностью, наличием в нем примесей анормального молока и посторонних веществ немолочного происхождения. Для ограничения механической загрязненности молока следует содержать в чистоте территорию ферм, благоустраивать подходы к фермам. В помещении коровника необходимо своевременно производить дезинфекцию, белить стены, менять подстилки, регулярно удалять навоз. Коров необходимо чистить, а наиболее загрязненные участки туловища обмывать теплой водой с добавлением дезинфицирующих веществ. При доении коров в стойле в переносные доильные ведра грубые и пыльные корма следует раздавать им не позднее, чем за час до доения, а непосредственно перед доением помещение коровника тщательно проветривать. В случае спадания доильного аппарата на подстилку не надевать его на вымя без предварительной очистки. Если выдаивание молока производится в переносные доильные ведра, то нельзя сливать его во фляги и хранить некоторое время в помещении, где стоят коровы. Соблюдение этих элементарных правил позволит получить молоко с минимальной механической загрязненностью, которая при нормальных условиях будет обусловливать и минимальную бактериальную его обсемененность.

Вымя коровы - неизбежный источник бактериального обсеменения молока. Находящиеся на поверхности соска микроорганизмы по сосковому каналу попадают внутрь вымени. В результате бактерицидного действия тканей вымени часть из них погибает. Однако наиболее стойкие формы микробов сохраняются и дальше размножаются. Их количество особенно велико в нижней части соскового канала. Первые струйки молока рекомендуется сдаивать в специальную кружку с черной сеточкой. Если таких кружек в хозяйстве нет, то можно использовать обычные поллитровые кружки. В этом случае на их верхний край с помощью обычной резинки закрепляется лоскут черной ткани. При использовании такой кружки легко заметить появление в молоке сгустков крови, гноя, хлопьев белка и слизи, которые свидетельствуют о заболевании вымени. Своевременно обнаружив это, можно предотвратить смешивание молока, полученного от заболевших животных, с общим удоем стада.

Молочная посуда и аппаратура в настоящее время становятся основным источником бактериального обсеменения молока. Причина этого в недостаточном уходе за сложным современным молочным оборудованием и в нарушении правил его мойки и дезинфекции.

Перед доением доярка или оператор машинного доения коров обязаны строго соблюдать правила личной гигиены: надеть чистый халат, не используемый ни для каких других работ, волосы убрать од косынку, руки по локоть тщательно вымыть с мылом и в заключение ополоснуть дезинфицирующим раствором. При получении молока необходимо использовать воду питьевого качества.

Следующим фактором, влияющим на санитарно-гигиеническое состояние молока, являются примеси анормального молока. Термин «анормальное» принят для обозначения любого молока, заметно отличающегося от нормального своим составом и свойствами. Можно выделить следующие наиболее распространенные типы анормального молока: 
молозиво; молоко коров, больных маститом; молоко коров с гинекологическими заболеваниями без поражения молочной железы и т.п. Примеси анормального молока отрицательно влияют и на технологические свойства всего молока. Они задерживают развитие в молоке полезной микрофлоры, придают ему неприятный вкус и запах, ухудшают сычужную свертываемость и снижают качество молочных продуктов. Посторонние вещества попадают в молоко разными путями: при скармливании кормов, содержащих вредные вещества, переходящие в молоко; нарушении инструкции по мойке и дезинфекции оборудования, а также в результате добавления посторонних веществ в молоко с различными целями. Наиболее часто в молоке встречаются вода, сода, антибиотики, консервирующие вещества, остатки моющих и дезинфицирующих веществ, а также пестициды.

Вода, добавляемая в молоко, может содержать патогенные и флюоресцирующие бактерии. В результате она может стать причиной заболевания людей и порчи молочных продуктов, вырабатываемых из такого молока.

Сода добавляется с целью снижения кислотности молока. Она благоприятствует развитию гнилостных бактерий, выделяющих токсины, делающие молоко опасным для потребителя.

Перекись водорода добавляется с целью консервирования молока. Однако при ее добавлении в молоке быстро развиваются окислительные процессы и ухудшается его вкус.

Пестициды - это химические вещества, которые применяются для борьбы с вредителями сельскохозяйственных растений и животных. В молоко они чаще всего попадают с кормами и с некачественной водой, и как правило водой из поверхностных источников, используемых для питья животных.

Еще раз обозначим и уточним некоторые моменты по проблеме содержания антибиотиков в молоке, затронутой выше. При лечении коров антибиотиками и смешивании полученного от них молока с общим удоем стада они могут попасть в молоко.

Большой вред следы антибиотиков наносят и технологическим свойствам молока. Сыр, изготовленный из молока со следами антибиотиков, имеет горький и гнилостный вкус и запах. Консистенция сыра становится слизистой, меловой или твердой, корка сыра размягчается. Сквашивание сливок, полученных из молока со следами антибиотиков, задерживается, а полученное из них масло характеризуется низкой термостойкостью. Особенно отрицательно влияют на технологические свойства молока пенициллин и стрептомицин. Антибиотики тетрациклинового ряда оказывают менее выраженное действие.

В настоящее время для отечественных молочных заводов задача № 1 - это сохранение и наращивание экспорта продукции. Однако из-за обнаружения в ней антибиотиков молочные продукты оказываются не соответствующими требованиям российского Технического регламента на молоко и молочную продукцию. Чтобы экспортировать продукцию за рубеж, необходимо соблюдать требования международного ветеринарного кодекса и директив ЕС относительно выполнения ветеринарно-санитарных норм и правил при выращивании, производстве, переработке, хранении, транспортировке и реализации продукции. Одним из требований стран ЕС является наличие и выполнение в стране программы мониторинга остатков вредных веществ у животных и в продукции животного происхождения. В Беларуси программа мониторинга за вредными веществами введена в 2004 году. В частности, директива (EWG) №2377/90 устанавливает жесткие требования к содержанию более чем 100 антибиотиков в молоке. В белорусской программе мониторинга таких антибиотиков 10. В соответствии с Директивой (EWG) № 2377/90, максимально допустимые концентрации не установлены для левомицетина (хлорамфеникола) и фуразолидона. Для этих веществ установлено положительное обнаружение. Предел обнаружения составляет 0,3 мкг/кг. В соответствии с СанПиН РБ 11-63 РБ 98 (последние изменения, которые были внесены 11.08.2009 г. по аналогии с российским законодательством), в молоке и молочной продукции не допускается содержание остаточного количества 4 антибиотиков: хлорамфеникола, тетрациклина, стрептомицина и пенициллина. Но в примечании отмечается, что содержание этих веществ не допускается «в пределах чувствительности методов определения». Сравнение допустимых уровней содержания потенциально опасных веществ в продуктах переработки молока в разных странах приведено в табл. 3. 
Таблица 3 - Сравнительный анализ нормативов разных стран по остаточному количеству антибиотиков в молоке-сырье (до 25 июня 2009 года)

\begin{tabular}{|c|c|c|c|}
\hline Антибиотик & РБ & $\overline{\mathrm{P}}$ & $\mathrm{EC}$ \\
\hline Левомицетин & Не допускается $(<0,01$ ед./г или 10 мкг/кг) & Не допускается & Не допускается \\
\hline Тетрациклин & Не допускается $(<0,01$ ед./Г или 10 мкг/кг) & Не допускается & 100 мкг/кГ \\
\hline Стрептомицин & Не допускается $(<0,5$ ед./Г или 500 мкг/кг) & Не допускается & $200 \mathrm{MКг/КГ}$ \\
\hline Пенициллин & Не допускается $(<0,01$ ед./Г или 10 мкг/кг) & Не допускается & 4 мкг/кг \\
\hline
\end{tabular}

Чтобы поставлять продукцию на зарубежные рынки, необходимо знать, какие методы для анализа образцов будут использовать лаборатории той или иной страны, а также знать чувствительность их методов. В зависимости от этого такие же методы контроля нужно применять и в Беларуси. От правильно выбранного метода контроля зависит сегодня судьба предприятий, поставляющих свою продукцию на российский рынок. При оценке соответствия молока и молочных продуктов белорусским требованиям возникает конкурирование разных методов исследования. Становится невозможным дать однозначную оценку на соответствие продукции требованиям белорусского законодательства. Это серьезно усложняет работу лабораторий. Другой проблемой в лабораторной практике является отсутствие в Беларуси государственного стандарта, устанавливающего требования к рецепторным методам анализа. В России такой стандарт введен. Один из вопросов, который он регулирует, - какой процент ложноположительных результатов допускает та или иная тест-система. Поэтому в нашей республике во взаимоотношениях хозяйств и предприятий нередки случаи несоответствия результатов испытаний. По результатам анализа лаборатории хозяйства содержание антибиотиков находится в пределах допустимых норм. При исследовании сырья на предприятии содержание антибиотика в 3-5 раз превышает значение, полученное в хозяйстве. Молоко бракуется как несоответствующее требованиям белорусского законодательства. Причина несоответствия кроется в использовании лабораториями разных методов анализа с разной чувствительностью. Во избежание подобных проблем специалисты ветцентра настоятельно рекомендуют поставщикам сырья и производителям использовать одинаковые методы анализа. Это общеевропейская практика.
Мойка и дезинфекция оборудования доильных установок - необходимое условие для получения молока высокого качества. После использования оборудования, молокопроводов, молочной посуды на них остается некоторое количество молока, что способствует развитию микроорганизмов. Плохо вымытая поверхность молочного оборудования - источник обсеменения молока бактериями и их спорами. Поэтому правильная и тщательная мойка оборудования - обязательное условие получения хорошего молока. Санитарную обработку оборудования выполняют до и после каждой дойки. Перед дойкой нужно горячей $\left(75-80^{\circ} \mathrm{C}\right)$ водой промыть доильные аппараты, молокопровод, охладитель молока и молочный насос, затем надо опорожнить молочную магистраль от остатков воды и настроить установку на режим «доение». После дойки доильные аппараты и молочное оборудование обрабатывают сначала теплой водой (не более $30-35^{\circ} \mathrm{C}$ ), затем моющими и дезинфицирующими растворами и горячей водой. Технология выполнения работ зависит от типа доильной установки и наличия оборудования для санитарной обработки. Все работы по санитарной обработке оборудования выполняют доярки и слесарь-наладчик. Для обеспечения содержания доильного и холодильного оборудования на высоком санитарном уровне необходимо постоянно соблюдать все технологические требования по проведению операций ежедневного и периодического техобслуживания.

В связи с тем, что одним из важных аспектов внешнеэкономической деятельности в Беларуси является экспорт молочной продукции уже только в 2010-2011 гг. разработано и введено в действие более 30 госстандартов на молочные продукты и методы их контроля. Стандарты на методы контроля молока и молочной продукции разработаны на основе международных стандартов и национальных стандартов Российской Федерации. 


\section{БИБЛИОГРАФИЯ}

Ковалёв Л.И. Организационно- технологические основы технического обслуживания и ремонта машин в молочном скотоводстве / Л.И. Ковалёв. - Минск: БГАТУ, 2012. - 224 с. ил.: - ISBN 978985-519-530-7.

Ковалёв Л.И. Динамика производства, экспорта, импорта молочных продуктов и перспективы развития молочной отрасли в Республике Беларусь / Л.И. Ковалёв, И.Л. Ковалёв // Аграрное решение. - Уфа. - 2012. № 4. С. 12-15.
Технический регламент Республики Беларусь «Молоко и молочная продукция. Безопасность» (ТР 2010/018/BY). Постановление Совета Министров Республики Беларусь 25.03.2010 № 431 . 